\title{
Analysis of healthy sitting behavior: Interface pressure distribution and subcutaneous tissue oxygenation
}

\author{
Jasper Reenalda, MSc; ${ }^{*}$ Paul Van Geffen, MSc; ${ }^{2}$ Marc Nederhand, PhD, MD; ${ }^{1}$ Michiel Jannink, PhD; ${ }^{1-2}$ \\ Maarten IJzerman, PhD; ${ }^{3}$ Hans Rietman, PhD, MD $^{1-2}$ \\ ${ }^{1}$ Roessingh Research and Development, Rehabilitation Centre het Roessingh, Enschede, the Netherlands; ${ }^{2}$ Laboratory \\ of Biomechanical Engineering, Faculty of Engineering Technology, and ${ }^{3}$ Department of Health Technology and \\ Services Research, University of Twente, Enschede, the Netherlands
}

\begin{abstract}
Pressure ulcers are a large problem in individuals who use a wheelchair for their mobility and have limited trunk stability and motor function. Because no relation between interface pressure and pressure ulcer development has been established and no clinical threshold for pressure ulcer development can be given, looking at the sitting behavior of nondisabled individuals is important. Nondisabled individuals do not develop pressure ulcers because they continuously shift posture. We analyzed the sitting behavior of 25 nondisabled male subjects by using a combination of interface pressure measurement and subcutaneous tissue oxygenation measurement by means of the Oxygen to See. These subjects shifted posture on average $7.8+/-5.2$ times an hour. These posture shifts were merely a combination of posture shifts in the frontal and sagittal plane. Subcutaneous oxygen saturation increased on average 2.2\% with each posture adjustment, indicating a positive effect of posture shifts on tissue viability. The results of this study can be used as a reference for seating interventions aimed at preventing pressure ulcers. Changing the sitting load at least every 8 minutes is recommended for wheelchair users.
\end{abstract}

Key words: dynamic sitting, interface pressure measurement, posture shift, pressure ulcer, recommendation, seating intervention, sitting behavior, tissue oxygenation, tissue viability, wheelchair seating.

\section{INTRODUCTION}

A pressure ulcer is defined as "localized injury to the skin and/or underlying tissue, usually over a bony prominence, as a result of pressure, or pressure in combination with shear and/or friction” [1]. Pressure ulcers are a large problem in individuals who use a wheelchair for their mobility. These individuals, especially those with limited trunk stability and limited motor function, sit in a wheelchair for long, consecutive periods of time, mostly in one posture. As a consequence, pressure ulcers can develop because of an unbalanced match between the external load and the ability of the skin and subcutaneous tissue to withstand that load. Prevalence values of pressure ulcers are high and have been reported to be 15.5 percent in U.S. healthcare facilities, with 28.0 percent of the pressure ulcers located at the sacrum and 17.2 percent at the buttocks [2]. Prevalence values of 18.1 percent have been reported in European standard and academic hospitals [3].

Abbreviations: $\mathrm{BMI}=$ body mass index, $\mathrm{DI}=$ dispersion index, FEM = finite element modeling, $\mathrm{O} 2 \mathrm{C}=$ Oxygen to See, $\mathrm{SCI}=$ spinal cord injury, $\mathrm{SD}=$ standard deviation, $\mathrm{SO}_{2}=$ oxygen saturation.

*Address all correspondence to Jasper Reenalda, MSc; Roessingh Research and Development, Rehabilitation Centre het Roessingh, Postbus 310, 7500 AH Enschede, the Netherlands; 0031-53-4875726. Email: i.reenalda@rrd.nl DOI:10.1682/JRRD.2008.12.0164 
A distinction can be made between superficial and deep pressure ulcers, both having a different etiology [46]. Deep pressure ulcers are understood to result from prolonged pressure and usually develop near the bony prominences where internal pressures are high. Superficial ulcers have been suggested to develop not as a result of pressure but rather as a result of shear and trauma to the tissue [7]. Unfortunately, no specific prevalence values for superficial or deep pressure ulcers are available.

Current clinical practices for assessing the risk of pressure ulcers focus on the interface pressure (the pressure between seat and body) during static load in one presumed optimal posture. Quantifying the risk of developing pressure ulcers during static load and assessing the influence of a specific seating device require a relevant measure of this risk. Despite the fact that much research has been performed on the etiology and prevention of pressure ulcers, a threshold value for the development of deep pressure ulcers, in terms of magnitude or duration, is still lacking. Moreover, the relation between interface pressure and the probability of pressure ulcer development is not consistent [8]. In addition, the developed pressure time curves predict that pressure ulcers will develop eventually, even with optimal pressure distribution [9-10]. This prediction has been confirmed by finite element modeling (FEM) techniques, and even with equally distributed pressures at the sitting interface, high pressure peaks have been shown to occur near the bony prominence [11-13].

It is intuitively obvious that individuals with intact sensory and motor function do not develop pressure ulcers because of a continuous variation in sitting posture, even if they sit on very uncomfortable seats for prolonged time periods. Extrapolation of this sitting behavior to the current practice for wheelchair users with spinal cord injury (SCI) has resulted in Agency for Healthcare Research and Quality guidelines advising that the user lift him- or herself every 20 minutes or be repositioned every 2 hours [14]. However, lifting creates severe loads on shoulders and arms and the ability to reposition is often limited in wheelchair users. Therefore, attempts have been made to minimize the load on the tissue by means of dynamic cushions and seating devices that create an alternating load to increase tissue oxygenation. These seating systems were demonstrated to positively influence interface pressure and skin oxygenation [1516]. Other methods, such as electric gluteal muscle stimulation also showed effectiveness in decreasing the inter- face pressure, which might restore blood flow [17]. However, it is not clear what the optimal frequency of these seating interventions must be to increase the viability of the tissue.

The sitting behavior of nondisabled individuals can serve as a guide to these seating interventions. The sitting behavior of these individuals prevents tissue damage, like pressure ulcers, and can serve as a reference value for the sitting behavior that should be adopted by individuals with SCI. Furthermore, knowledge of healthy sitting behavior could also be valuable in the development of dynamic seating devices that can alter the load on the tissue to prevent pressure ulcers. An analysis of healthy sitting behavior was carried out by Linder-Ganz et al. [18], who concluded that nondisabled subjects change their posture approximately every 9 minutes in the sagittal plane and approximately every 6 minutes in the frontal plane, as measured with pressure sensors and trunk movement analysis. Unfortunately, this study focused only on trunk movements and the external load on the tissue, as quantified by the interface pressure. However, an important determinant of deep pressure ulcer development is the internal pressure beneath the ischial tuberosities. FEM [11-13] and test-buttock experiments with pressure sensors [19-20] have shown that the internal pressure exceeds the external pressure and that there are peaks in the muscle tissue due to compression of tissue beneath the bony prominences. Deep pressure ulcers originate in the muscle layer beneath the ischial tuberosities. Local subcutaneous tissue oxygenation is a direct derivative of the viability of the muscle tissue and is directly influenced by the internal pressure, which causes compression and occlusion. Up to a measurement depth of approximately $8 \mathrm{~mm}$, the Oxygen to See (O2C) (LEA Medizintechnik; Giessen, Germany) is currently the only device capable of noninvasive measurement of (sub)cutaneous tissue oxygenation.

Because no relation between interface pressure and pressure ulcer development has been established and, as such, no clinical threshold for pressure ulcer development can be given, reference guidelines for dynamic sitting behavior might be obtained from knowledge of nondisabled subjects' sitting behavior. Therefore, the objective of this article is to describe healthy dynamic sitting behavior in terms of variation in pressure distribution and to investigate the effects of such sitting behavior on subcutaneous tissue oxygenation as a function of time. 


\section{METHODS}

A cross-sectional study was performed. The study design was approved by the local medical and ethical committee.

\section{Subjects}

A total of 25 nondisabled subjects was recruited (mean \pm standard deviation [SD] age $=26.0 \pm 3.9 \mathrm{yr}$, height $=1.90 \pm 0.07 \mathrm{~m}$, weight $=80.2 \pm 9.5 \mathrm{~kg}$, body mass index $[\mathrm{BMI}]=22.7 \pm 2.2$ ). All subjects were males between the ages of 18 and 50. Exclusion criteria were vascular diseases that could disturb blood flow (like diabetes) and the presence of pressure ulcers or other skin diseases. These conditions were checked by the medical staff before the study.

\section{Equipment}

A standard Ibis comfort wheelchair was used for this study (Handicare BV; Helmond, the Netherlands). The cushion of the Ibis comfort wheelchair was replaced with a custom-made cushion (Welzorg Special Products; Oldenzaal, the Netherlands). The wheelchair was equipped with a Tekscan CONFORMat pressure-mapping device (Tekscan Inc; Boston, Massachusetts) that measured the pressure distribution on the sitting surface. This pressuremapping device consists of 1,024 pressure sensors that are connected in a flexible way to minimize the hammocking effect. Sample rate of the pressure-mapping device was set at $1 \mathrm{~Hz}$. The pressure-mapping device was calibrated weekly according to the manufacturer's guidelines.

Tissue perfusion and oxygenation were measured with the O2C. The O2C is a diagnostic device that uses laser Doppler flowmetry and diffuse-reflectance spectroscopy for the noninvasive determination of oxygen supply in blood-perfused tissue. The O2C transmits continuous wave laser light ( $830 \mathrm{~nm}$ and $30 \mathrm{~mW}$ ) and white light (500-800 nm, $1 \mathrm{~nm}$ resolution, $20 \mathrm{~W}$ ) to tissue, where it is scattered and collected on the skin surface at fibers in the probe. The sample frequency of the $\mathrm{O} 2 \mathrm{C}$ is $0.5 \mathrm{~Hz}$; therefore, it is capable of measuring the dynamic response in blood flow. The data are analyzed by comparison with prerecorded deoxygenated and oxygenated hemoglobin spectra. The $\mathrm{O} 2 \mathrm{C}$ has four output parameters [21] of which only the percentage of oxygen saturation $\left(\mathrm{SO}_{2}\right)$, which is a relative measure and reflects the oxygen saturation of hemoglobin, was used in this study. The fiber-optic probes used by $\mathrm{O} 2 \mathrm{C}$ incorporate both the laser
Doppler method and broadband light spectroscopy techniques and measures at a maximum depth of approximately $8 \mathrm{~mm}$. The probe was attached to the skin with surgical tape. The probe for subcutaneous measurement was attached beneath the right tuberosity.

\section{Experimental Design}

Subjects reported to the laboratory once and were instructed beforehand by a letter describing the experimental procedure. They also signed an informed consent.

Prior to the study, the probes of the O2C were securely attached to the skin with adhesive medical tape right beneath the ischial tuberosities. The probes were custom-made to prevent interference with the seating interface. As a result, no confounding effects of the probes on the measurements occurred. To prevent probe dislocation relative to the ischial tuberosity as a result of soft tissue displacement when sitting, the ischial tuberosity was localized by means of palpation with the subject lying on his side with his hips and knees flexed $90^{\circ}$ to imitate the sitting position. The adhesive tape prevented the probe from moving as a result of posture shifts during the study. After attachment of the probe, the subject was transferred to the experimental wheelchair. Foot support was adjusted according to subject characteristics. Subjects were instructed to sit as comfortably and naturally as possible. After instruction, the measurement started and lasted for 60 minutes. A television showing a movie was placed at the horizontal level to distract the subjects. Temperature in the room was controlled at $21^{\circ} \mathrm{C}$.

\section{Outcome Measures}

Interface pressure, as measured with the pressuremapping device, is expressed by the dispersion index (DI) [22]. DI is a relative measure of the load on the sitting surface and is defined as the load on one tuberal zone divided by the total load on the sitting surface as measured with the pressure-mapping device. The advantage of expressing the pressure data in a relative measure like DI is that reliability issues like creep and drift are bypassed. Raw data from the pressure mapping device were exported in ASCII (American Standard Code for Information Interchange) format. A MATLAB script (The MathWorks; Nattick, Massachusetts) was used to define pressure peaks in a region that was expected to surround the ischial tuberosities; this region was defined by a zone of $6 \times$ 6 pressure sensors $(9 \times 9 \mathrm{~cm})$ to calculate the DI. A lower DI value means that the load is more evenly distributed (i.e., dispersed) on the total sitting contact surface as 
opposed to being located at two points (e.g., the ischial tuberosities). The DI value depends on the total contact surface, and therefore, DI values are not comparable interindividually.

Although the O2C provides information about tissue oxygenation as well as tissue perfusion and hemoglobin content and velocity, only oxygenation values $\left(\% \mathrm{SO}_{2}\right)$ were used in this experiment. Tissue oxygenation is a direct indicator of the viability of the tissue and is a result of tissue perfusion. From a physiological perspective, $\mathrm{SO}_{2}$ is expected to decrease gradually because of occlusion of the blood vessels as a result of the external load and then sharply increase after a posture shift as a result of the reflow of blood. A fifth-order Butterworth filter with a cutoff frequency of $0.1 \mathrm{~Hz}$ was used to filter the DI and $\mathrm{SO}_{2}$ data for random noise.

\section{Data Analysis}

To establish a pattern of healthy sitting behavior, we were interested in the frequency of the posture shifts and the resulting change in subcutaneous tissue oxygenation.

Posture shifts were defined by analysis of the DI data of both ischial tuberosities. To calculate posture shifts in the sagittal plane, we determined the sum of the DI values of the right and left ischial tuberosities. For movement in the frontal plane, we calculated the ratio of the mean DI values of the left and right ischial tuberosities. Threshold values for sagittal and frontal movements of \pm 10 percent were defined. When the signal exceeds the threshold, a posture shift is identified. Posture shifts that occurred within 1 minute were regarded as one posture shift. Posture shifts were counted and related to their respective variation in $\mathrm{SO}_{2}$ values. Average $\mathrm{SO}_{2}$ values of the time frames of 1 minute before and 1 minute after the posture shift were calculated. The difference between these two average values was defined as the variation in tissue oxygenation as a result of a single posture shift.

Average values of the variation in oxygenation as a result of the total number of posture shifts were calculated for each subject, along with posture shifts in the sagittal and frontal planes.

\section{RESULTS}

On the basis of changes in pressure distribution, the nondisabled subjects changed their posture on average (mean \pm SD) $7.8 \pm 5.2$ times an hour. These posture shifts were mostly a combination of posture shifts in the sagittal and frontal planes. Approximately 80 percent of posture shifts were movements in the sagittal plane and 20 percent were movements in the frontal plane. The posture shifts corresponded to an average increase in subcutaneous tissue oxygenation of $2.2 \pm 2.4$ percent. Figure 1 gives a typical example of the DI and $\mathrm{SO}_{2}$ values of one research subject during the measurement period, with the posture shifts identified. As can be seen in Figure 1, this subject employed eight posture shifts (t1-t8) during the 60-minute measurement period, based on the DI values as indicated in the upper row. $\mathrm{SO}_{2}$ values are displayed in the lower row. Clearly visible is the physiologically expected pattern of gradually decreasing subcutaneous $\mathrm{SO}_{2}$ values, which increased rapidly after a posture shift.

Tissue oxygenation data were complete for all but one subject. The Table describes the average values for $\mathrm{SO}_{2}$, the number of posture shifts and their corresponding change in $\mathrm{SO}_{2}$, and identified patterns in tissue oxygenation for all subjects. The Table includes average values for the different patterns in tissue oxygenation values.

In the subcutaneous tissue oxygenation data, three patterns can be identified: the physiologically expected pattern, the physiologically inconsistent pattern, and the stable pattern in which no reaction in oxygenation is observed. The physiologically expected pattern is characterized by a slow decrease in tissue oxygenation followed by a rapid increase as a result of a posture shift. By contrast, the physiologically inconsistent pattern is characterized by very low tissue oxygenation values of 11 percent on average and a slow increase in tissue oxygenation values followed by a rapid decrease as a result of a posture shift. The number of posture shifts is comparable to the number of

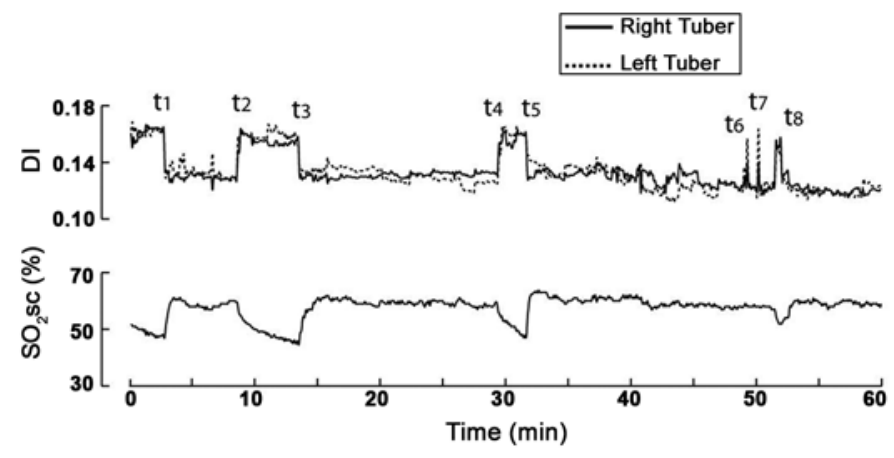

Figure 1.

Typical example of dispersion index (DI) and subcutaneous oxygen saturation $\left(\mathrm{SO}_{2} \mathrm{Sc}\right)$, with identified posture shifts (t1-t8). 
Table.

Average values for oxygen saturation $\left(\mathrm{SO}_{2}\right)$, number of posture shifts, and corresponding change in $\mathrm{SO}_{2}$ for all subjects, including identified reaction pattern in tissue oxygenation: physiologically expected ("Physiological”), physiologically inconsistent ("Inconsistent”), and stable.

\begin{tabular}{|c|c|c|c|c|}
\hline Subject & Pattern & Average $\mathrm{SO}_{2}(\%)$ & Posture Shifts (No.) & $\Delta \mathrm{SO}_{2}(\%)$ \\
\hline 1 & Physiological & 58.0 & 14 & 0.7 \\
\hline 2 & Physiological & 48.9 & 9 & 0.8 \\
\hline 3 & Physiological & 57.4 & 10 & 2.2 \\
\hline 4 & Physiological & 53.0 & 6 & 1.3 \\
\hline 5 & Physiological & 32.3 & 14 & 3.7 \\
\hline 6 & Physiological & 50.1 & 15 & 5.4 \\
\hline 9 & Physiological & 38.2 & 5 & 3.0 \\
\hline 10 & Physiological & 16.0 & 4 & 1.1 \\
\hline 11 & Physiological & 54.7 & 1 & 3.6 \\
\hline 12 & Physiological & 56.6 & 3 & 8.7 \\
\hline 13 & NA & NA & 1 & NA \\
\hline 17 & Physiological & 48.2 & 8 & 4.9 \\
\hline 18 & Physiological & 57.9 & 7 & 0.1 \\
\hline 19 & Physiological & 59.9 & 4 & 0.8 \\
\hline 20 & Physiological & 28.3 & 2 & 1.1 \\
\hline 21 & Stable & 32.7 & 0 & 0.0 \\
\hline 22 & Stable & 59.4 & 1 & 0.0 \\
\hline 23 & Physiological & 61.3 & 20 & 0.9 \\
\hline 24 & Inconsistent & 11.9 & 5 & 0.0 \\
\hline 25 & Physiological & 32.6 & 9 & 2.1 \\
\hline$\overline{\text { Mean } \pm \text { SD }}$ & Physiological $(n=19)$ & 44.9 & $7.8 \pm 5.2$ & $2.2 \pm 2.4$ \\
\hline
\end{tabular}

posture shifts observed in the physiologically expected pattern. The third pattern is characterized by a stable tissue oxygenation value and a lack of posture shifts.

The physiologically expected pattern was displayed by 19 of the 24 subjects. The physiologically inconsistent pattern was displayed by only 2 of the 24 subjects and was excluded from analysis because of extremely low oxygenation values. These values are commonly considered extremely hypoxic and therefore regarded as highly predictive of the onset of tissue failure [23]. The third pattern was characterized by a stable tissue oxygenation value and was identified in 3 of the 24 subjects. Because of the lack of posture shifts and the stable oxygenation values, these subjects were also excluded from further analyses.
No differences in BMI values were found among the three groups. As a result, analyses were performed on the 19 subjects displaying the physiologically expected pattern. Typical examples of four subjects displaying the physiologically expected pattern can be found in Figure 2 .

\section{DISCUSSION AND CONCLUSIONS}

The nondisabled subjects changed their sitting position on average $7.8 \pm 5.2$ times an hour. Subcutaneous oxygen saturation increased on average 2.2 percent with each posture adjustment, indicating the positive effects of posture shifts on tissue viability. Posture shifts in our study were approximately 80 percent movements in the 


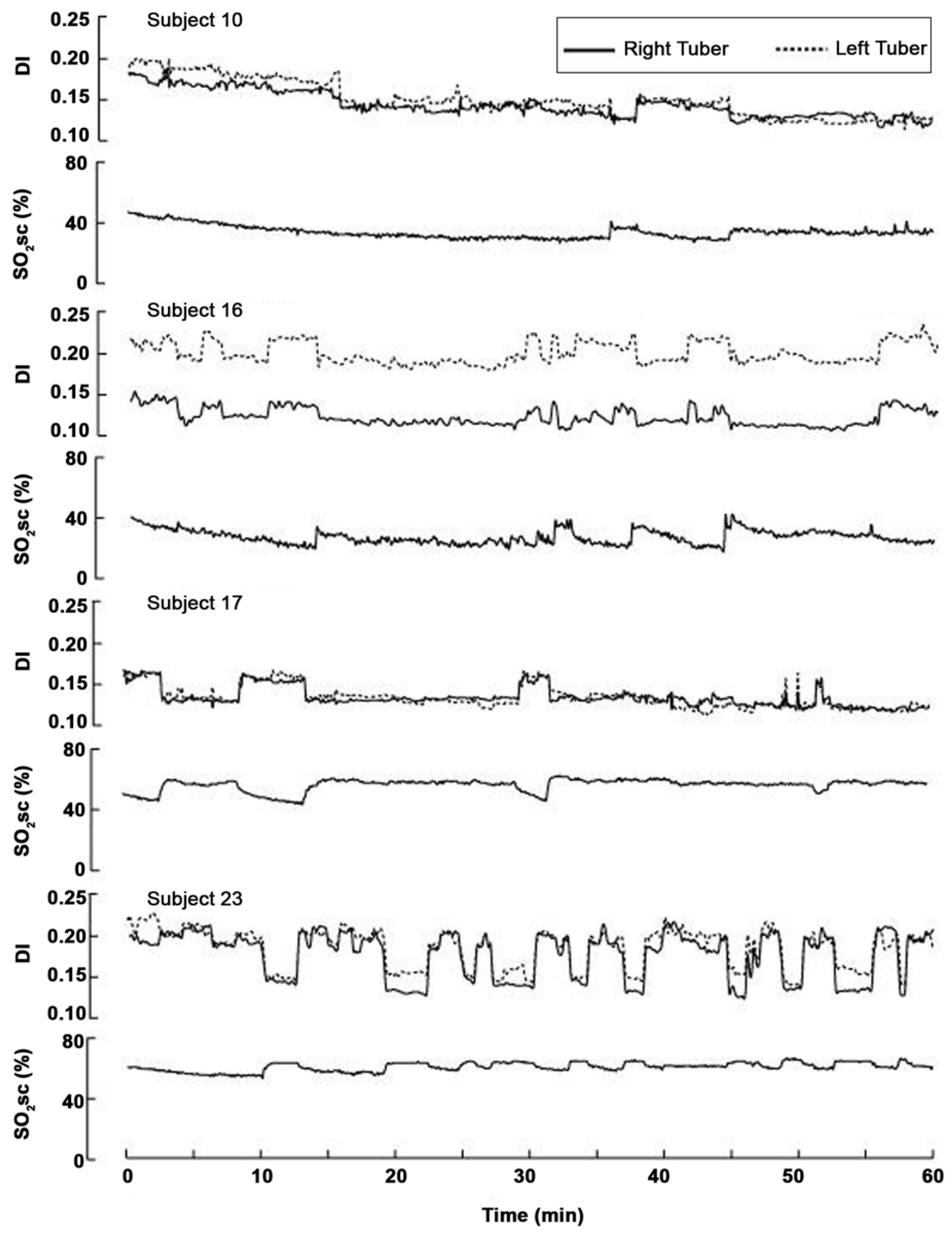

Figure 2.

Typical examples (subjects 10, 16, 17, and 23) of dispersion index (DI) and subcutaneous oxygen saturation ( $\left.\mathrm{SO}_{2} \mathrm{Sc}\right)$ across time, all displaying physiologically expected pattern. 
sagittal plane and 20 percent movements in the frontal plane. The results of this study can be used as a reference for dynamic seating devices aimed at preventing pressure ulcers in individuals with limited sensory and motor function who use a wheelchair for mobility. The magnitude of the posture shifts is on the same order as the magnitude in Linder-Ganz et al.'s study [18]. In that study, they found that nondisabled subjects changed their posture approximately every 9 minutes in the sagittal plane (6.7 times an hour) and approximately every 6 minutes in the frontal plane (10 times an hour), as measured with pressure sensors and movement analysis. Compared with Linder-Ganz et al.'s study, subjects in the present study moved more frequently in the sagittal plane ( 80\%) and less frequently in the frontal plane ( 20\%). Linder-Ganz et al. based their analysis of nondisabled sitting behavior on pressure measurement (in order to define posture shifts in the frontal plane) and trunk-motion analysis (in order to define posture shifts in the sagittal plane). Linder-Ganz et al.'s study only quantified variation in external pressure without considering internal pressure. The present study used measurement of the DI to quantify posture shifts and used the measurement of subcutaneous tissue oxygenation as a determinant of internal pressure. In the majority of the subjects, the posture shifts were accompanied by an increase in subcutaneous $\mathrm{SO}_{2}$. As a result of the posture shifts, subcutaneous $\mathrm{SO}_{2}$ increased on average 2.2 percent, which indicates the positive effects of posture shifts on tissue viability. Yet to be studied is whether the value of 2.2 percent is sufficient to maintain tissue viability in subjects with limited motor function who use a wheelchair for mobility.

A more in-depth look at the subcutaneous tissue oxygenation revealed three distinct patterns. The first pattern followed a physiological pathway that was expected in advance and, indeed, was exhibited by most subjects. Because of the external load, the buttock tissue is compressed against the bony structures of the pelvis. As a result, the internal load increases. This increase has previously been shown with FEM and experiments with test buttocks [11-13,19,20]. The increase in internal load causes compression of the tissue and occlusion of the blood and lymphatic vessels, resulting in a decrease in tissue oxygenation. Posture shifts can relieve the tissue and restore blood flow, thereby elevating the tissue oxygenation values. This process continues and repeats during prolonged sitting.
The second observed pattern was physiologically inconsistent. The two subjects who displayed this pattern had very low average values of tissue $\mathrm{SO}_{2}$ at approximately 11 percent. This value is commonly considered extremely hypoxic and highly predictive of the onset of tissue failure [23]. Because these oxygenation values were extremely low, they were likely the result of measurement errors. Therefore, these subjects were excluded from the analysis.

In the third pattern, as exhibited by three subjects, average tissue $\mathrm{SO}_{2}$ values were comparable with the average values in the physiologically expected group; however, no changes in pressure distribution and tissue oxygenation could be found. An explanation for this phenomenon could be that these subjects do have internal tissue characteristics, reflected in a different anatomy and geometry. This difference may have prevented the muscle tissue from deformation or occlusion, although no relation with the subjects' BMI could be established. However, a more plausible explanation could be that, just as in the case of the physiologically inconsistent pattern, measurement errors are responsible for these results. Despite the care with which the probes were placed, misplacement of the probes might have caused these unexpected values.

The present study uses a relative measure of the interface pressure to describe the pressure distribution. Maximum pressures and average pressures have been shown to possess low test-retest reliability [24]. The DI has been proposed as a relative measure to describe the distribution of pressure on the tuberal regions compared with the total contact surface and has been shown to have good reliability [24]. A weak qualitative relation appears to exist between interface pressure and the development of pressure ulcers [8]. As a result, no conclusive clinical threshold for the interface pressure can be given. In addition, individual characteristics, like level of mobility, body composition, nutritional state, and other comobordities, do play a role. Furthermore, the measurement of interface pressure has low internal validity for the prediction of pressure ulcers and an incongruent relation exists between pressure magnitude and duration. This results in the fact that no quantification of the predictive or prognostic value of interface pressure can be given [8]. To overcome this problem, the present study used the measurement of subcutaneous tissue perfusion and $\mathrm{SO}_{2}$ with the $\mathrm{O} 2 \mathrm{C}$. At present, the $\mathrm{O} 2 \mathrm{C}$ is the only device capable of measuring the perfusion and oxygenation of the subcutaneous tissue noninvasively up to a maximum depth of 
approximately $8 \mathrm{~mm}$. Muscle blood flow has been reliably measured by the xenon clearance method [4]. However, this technique is invasive and requires injections with radioactive tracer material. Other measurement techniques used in the field of pressure ulcer research, like laser Doppler flowmetry [25-26], transcutaneous oxygen tension $[15,16]$ and, tissue reflectance spectrophotrometry [27-28], do not possess penetration depths sufficient to reach the muscle tissue and are confined to measurement of perfusion and $\mathrm{SO}_{2}$ of the skin only. However, muscle tissue is most susceptible to developing pressure ulcers because of its high metabolic demand [29]. In addition, FEM has shown that internal stresses are highest in the muscle tissue right beneath the bone. During sitting, the gluteus maximus muscle is located at a depth of approximately 7 to $15 \mathrm{~mm}$, depending on the anatomy and geometry of the other tissue structures. This means that in this study, part of the signal from the subcutaneous measurement is coming from the gluteus maximus muscle and part of the signal is coming from other subcutaneous structures. Obtaining data from only the muscle requires an even larger penetration depth, which cannot be reached noninvasively at present.

In this study, a subject population of young nondisabled males was used. This provides a homogeneous subject population but has drawbacks for universal applicability of the results. As a result of immobilization and atrophy, differences in skin anatomy and vascularization exist between subjects with and without SCI [30]. Consequently, the capability of the tissue of subjects with SCI to withstand external load will likely be reduced. To imitate the sitting situation of individuals who use a wheelchair for mobility, the nondisabled subjects in this study sat in a wheelchair during the measurement period. However, this means that the displayed sitting behavior might not have fully reflected their normal sitting behavior in their seat of choice. Caution must therefore be taken in generalizing the results of this study to the population with SCI.

The results of the present study suggest that nondisabled subjects move on average 7.8 times an hour in order to relieve the subcutaneous tissue and increase tissue viability. Posture shifts were composed mostly of movements in the sagittal plane $(\sim 80 \%)$ and movements in the frontal plane $(\sim 20 \%)$. One can conclude from these results that shifting posture at least every 8 minutes is advisable for maintenance of tissue viability in wheelchair users. The results of this study can be used as refer- ence values for dynamic seating devices or seating interventions aimed at alternating the seating load to prevent pressure ulcers in wheelchair users. Future studies should address the effect of use of this reference value for healthy sitting behavior on the subcutaneous tissue oxygenation of wheelchair users with limited mobility. Subcutaneous $\mathrm{SO}_{2}$ increases on average 2.2 percent with each posture adjustment, indicating the positive effects of posture shift on tissue viability. Future studies should address the relevance of this value for the population with SCI.

\section{ACKNOWLEDGMENTS}

\section{Author Contributions:}

Study concept and design: J. Reenalda. Acquisition of data: J. Reenalda, P. Van Geffen. Analysis and interpretation of data: J. Reenalda, P. Van Geffen. Drafting of manuscript: J. Reenalda. Statistical analysis: J. Reenalda, P. Van Geffen. Critical revision of manuscript for intellectual content: M. Nederhand, M. Jannink, M. IJzerman, H. Rietman.

Study supervision: M. Jannink, M. IJzerman, H. Rietman.

Obtained funding: M. IJzerman.

Financial Disclosures: The authors have declared that no competing interests exist.

Funding/Support: This material was based on work partly funded by the Dutch Ministry of Economic Affairs, SenterNovem (grant TSIT3043).

Additional Contributions: Dr. Jannink currently works for Oost NV, Enschede, the Netherlands.

Participant Follow-Up: The authors plan to inform participants of the publication of this study.

\section{REFERENCES}

1. Black J, Baharestani M, Cuddigan J, Dorner B, Edsberg L, Langemo D, Posthauer ME, Ratliff C, Taler G, National Pressure Ulcer Advisory Panel. National Pressure Ulcer Advisory Panel's updated pressure ulcer staging system. Urol Nurs. 2007;27(2):144-50, 156. [PMID: 17494455]

2. Vangilder C, Macfarlane GD, Meyer S. Results of nine international pressure ulcer prevalence surveys: 1989 to 2005. Ostomy Wound Manage. 2008;54(2):40-54. [PMID: 18382042]

3. Vanderwee K, Clark M, Dealey C, Gunningberg L, Defloor T. Pressure ulcer prevalence in Europe: A pilot study. J Eval Clin Pract. 2007;13(2):227-35. [PMID: 17378869] DOI:10.1111/j.1365-2753.2006.00684.x

4. Levine SP, Kett RL, Gross MD, Wilson BA, Cederna PS, Juni JE. Blood flow in the gluteus maximus of seated 
individuals during electrical muscle stimulation. Arch Phys Med Rehabil. 1990;71(9):682-86. [PMID: 2375675]

5. Bouten CVC, Bosboom EMH, Oomens CWJ. The etiology of pressure sores: A tissue and cell mechanics approach. In: Van der Woude LHV, Hopman MTE, Van Kemenade CH, editors. Biomedical aspects of manual wheelchair propulsion. Amsterdam (the Netherlands): IOS Press; 1999. p. 52-62.

6. Bouten CV, Oomens CW, Baaijens FP, Bader DL. The etiology of pressure ulcers: Skin deep or muscle bound? Arch Phys Med Rehabil. 2003;84(4):616-19. [PMID: 12690603] DOI:10.1053/apmr.2003.50038

7. Brienza D. Pressure ulcers: More questions than answers. Proceedings of the 23d International Seating Symposium; 2007 Mar 8-10; Orlando, FL. Pittsburgh (PA): University of Pittsburgh; 2007.

8. Reenalda J, Nederhand M, Jannink M, IJzerman M. The clinical use of interface pressure to predict pressure ulcer development: A systematic review. Assist Technol. Forthcoming 2009.

9. Kosiak M. Etiology and pathology of ischemic ulcers. Arch Phys Med Rehabil. 1959;40(2):62-69. [PMID: 13618101]

10. Reswick JB, Rogers JE. Experience at Rancho Los Amigos Hospital with devices and techniques to prevent pressure sores. In: Kenedi RM, Cowden JM, Scales JT, editors. Bedsore biomechanics. London (UK): Macmillan; 1976. p. 301-10.

11. Oomens CWJ, Bressers OFJT, Bosboom EM, Bouten CV, Blader DL. Can loaded interface characteristics influence strain distributions in muscle adjacent to bony prominences? Comput Methods Biomech Biomed Engin. 2003; 6(3):171-80. [PMID: 12888429]

DOI:10.1080/1025584031000121034

12. Linder-Ganz E, Engelberg S, Scheinowitz M, Gefen A. Pressure-time cell death threshold for albino skeletal muscles as related to pressure sore biomechanics. J Biomech. 2006;39(14):2725-32. [PMID: 16199045]

DOI:10.1016/j.jbiomech.2005.08.010

13. Linder-Ganz E, Shabshin N, Itzchak Y, Gefen A. Assessment of mechanical conditions in sub-dermal tissues during sitting: A combined experimental-MRI and finite element approach. J Biomech. 2007;40(7):1443-54. [PMID: 16920122] DOI:10.1016/j.jbiomech.2006.06.020

14. Agency for Health Care Policy and Research (AHCPR). Treatment of pressure ulcers. In: Clinical Practice Guidelines No. 15. Publication No. 95-0652. Washington (DC): U.S. Department of Health and Human Services; 1994.

15. Bader DL. The recovery characteristics of soft tissues following repeated loading. J Rehabil Res Dev. 1990;27(2): 141-50. [PMID: 2366198]

16. Makhsous M, Lin F, Hendrix RW, Hepler M, Zhang LQ. Sitting with adjustable ischial and back supports: Biomechanical changes. Spine. 2003;28(11):1113-21; discussion

\section{1-22. [PMID: 12782977]}

DOI:10.1097/00007632-200306010-00006

17. Van Londen A, Herwegh M, Van der Zee CH, Daffertshofer A, Smit CA, Niezen A, Janssen TW. The effect of surface electric stimulation of the gluteal muscles on the interface pressure in seated people with spinal cord injury. Arch Phys Med Rehabil. 2008;89(9):1724-32.

[PMID: 18760157]

DOI:10.1016/j.apmr.2008.02.028

18. Linder-Ganz E, Scheinowitz M, Yizhar Z, Margulies SS, Gefen A. How do normals move during prolonged wheelchair-sitting? Technol Health Care. 2007;15(3):198-202.

[PMID: 17473399]

19. Staarink HAM. Sitting posture, comfort and pressure: Assessing the quality of wheelchair cushions. Delft (the Netherlands): Delft University Press; 1995.

20. Gefen A, Levine J. The false premise in measuring bodysupport interface pressures for preventing serious pressure ulcers. J Med Eng Technol. 2007;31(5):375-80.

[PMID: 17701783]

DOI:10.1080/03091900601165256

21. Beckert S, Witte MB, Königsrainer A, Coerper S. The impact of the Micro-Lightguide $\mathrm{O} 2 \mathrm{C}$ for the quantification of tissue ischemia in diabetic foot ulcers. Diabetes Care. 2004;27(12):2863-67. [PMID: 155562198]

DOI:10.2337/diacare.27.12.2863

22. Sprigle S, Press L, Davis K. Development of uniform terminology and procedures to describe wheelchair cushion characteristics. J Rehabil Res Dev. 2001;38(4):449-61.

[PMID: 11563498]

23. Hölzle F, Swaid S, Nolte D, Wolff KD. Nutritive perfusion at donor site after microvascular fibula transfer. Microsurgery. 2003;23(4):306-12. [PMID: 12942519] DOI: $10.1002 /$ micr. 10143

24. Sprigle S, Dunlop W, Press L. Reliability of bench tests of Interface pressure. Assist Technol. 2003;15(1):49-57. [PMID: 14760981]

25. Mayrovitz HN, Smith JR. Adaptive skin blood flow increases during hip-down lying in elderly women. Adv Wound Care. 1999;12(6):295-301. [PMID: 10687548]

26. Mayrovitz HN, Macdonald J, Smith JR. Blood perfusion hyperemia in response to graded loading of human heels assessed by laser-Doppler imaging. Clin Physiol. 1999; 19(5):351-59. [PMID: 10516885] DOI:10.1046/j.1365-2281.1999.00184.X

27. Sprigle S, Linden M, Riordan B. Characterizing reactive hyperemia via tissue reflectance spectroscopy in response to an ischemic load across gender, age, skin pigmentation and diabetes. Med Eng Phys. 2002;24(10):651-61.

[PMID: 12460724] DOI:10.1016/S1350-4533(02)00149-2 
JRRD, Volume 46, Number 5, 2009

28. Sprigle S, Linden M, Riordan B. Analysis of localized erythema using clinical indicators and spectroscopy. Ostomy Wound Manage. 2003;49(3):42-52. [PMID: 12732750]

29. Salcido R, Fisher SB, Donofrio JC, Bieschke N, Knapp C, Liang R, LeGrand EK, Carney JM. An animal model and computer-controlled surface pressure delivery system for the production of pressure ulcers. J Rehabil Res Dev. 1995; 32(2):149-61. [PMID: 7562655]
30. Li Z, Leung JY, Tam EW, Mak AF. Wavelet analysis of skin blood oscillations in persons with spinal cord injury and able-bodied subjects. Arch Phys Med Rehabil. 2006; 87(9):1207-12. [PMID: 16935056] DOI:10.1016/j.apmr.2006.05.025

Submitted for publication December 18, 2008. Accepted in revised form March 23, 2009. 